\title{
Bone morphogenetic protein-4 is required for mesoderm formation and patterning in the mouse
}

\author{
Glenn Winnier, ${ }^{1}$ Manfred Blessing, ${ }^{1,2}$ Patricia A. Labosky, and Brigid L.M. Hogan \\ Howard Hughes Medical Institute and Department of Cell Biology, Vanderbilt University Medical School, Nashville, \\ Tennessee 37232-2175 USA
}

\begin{abstract}
Bone morphogenetic protein-4 (BMP-4) is a member of the TGF- $\beta$ superfamily of polypeptide signaling molecules, closely related to BMP-2 and to Drosophila decapentaplegic (DPP). To elucidate the role of BMP-4 in mouse development the gene has been inactivated by homologous recombination in ES cells. Homozygous mutant Bmp-4 ${ }^{\text {tm1blh }}$ embryos die between 6.5 and 9.5 days p.c., with a variable phenotype. Most Bmp-4 $4^{\text {tm } 1 b l h}$ embryos do not proceed beyond the egg cylinder stage, do not express the mesodermal marker $T(B r a c h y u r y)$, and show little or no mesodermal differentiation. Some homozygous mutants develop to the head fold or beating heart/early somite stage or beyond. However, they are developmentally retarded and have truncated or disorganized posterior structures and a reduction in extraembryonic mesoderm, including blood islands. These results provide direct genetic evidence that $\mathrm{BMP}-4$ is essential for several different processes in early mouse development, beginning with gastrulation and mesoderm formation. Moreover, in the presumed absence of zygotic ligand, it appears that homozygous mutants can be rescued partially by related proteins or by maternal BMP-4.
\end{abstract}

[Key Words: BMP-4; mouse embryo; targeted mutation; lethal embryonic phenotype]

Received May 3, 1995; revised version accepted July 12, 1995.

Bone morphogenetic proteins-2 and -4 (BMP-2 and BMP4) are two closely related members of the transforming growth factor (TGF)- $\beta$ superfamily of secreted polypeptide signaling molecules (for review, see Kingsley 1994; Hogan 1995). The carboxy-terminal mature regions of the two proteins are $92 \%$ identical at the amino acid level. Moreover, they have been highly conserved during evolution; in Drosophila a single gene, decapentaplegic $(d p p)$, encodes a protein with $\sim 75 \%$ sequence identity to BMP-2 and BMP-4 in the carboxy-terminal mature region. At the functional level, human BMP-4 can rescue the dorsal-ventral pattern defects of $d p p$ null mutants, and Drosophila DPP protein can induce ectopic bone in mice (Padgett et al. 1993; Sampath et al. 1993). Genetic analysis has shown that DPP is required at several different stages of Drosophila development. It acts as a dorsalizing morphogen in the dorsal-ventral patterning of the blastoderm embryo, mediates an inductive interaction between mesoderm and endoderm in the larval midgut, and plays a role in the proximal-distal patterning of the leg and wing imaginal discs (for review, see Campbell et al. 1993; Diaz-Benjumea and Cohen 1993; Wall and Hogan 1994).

The striking evolutionary conservation of BMP-4 and

\footnotetext{
${ }^{1}$ These authors contributed equally to this work. ${ }^{2}$ Present address: I. Medical Department, Johannes Gutenberg University, Mainz, Germany.
}

DPP supports the idea that BMP-4 plays crucial roles in development. Studies on the temporal and spatial patterns of $B m p-4$ expression in the mouse embryo are consistent with this hypothesis. Low levels of $B m p-4$ RNA have been detected as early as 6.5 days postcoitum (p.c.), around the time of gastrulation (Jones et al. 1991; Johansson and Wiles 1995; Fig. 1A,B) and by 7.5 days p.c. transcripts can be localized in the allantois, amnion, and posterior primitive streak (Jones et al. 1991; Fig. 1C,D). Expression is maintained in these regions through 8.5 and 9.0 days p.c. and is also seen in the mesoderm around the hindgut and foregut and in the ventral lateral mesoderm of the posterior body wall and gut (splanchopleure and somatopleure) (Jones et al. 1991; Fig. 1F). As development proceeds, transcripts become localized to specific regions of the myocardium of the heart, the branchial arches, otic vesicle, and diencephalon. In later embryos, $B m p-4$ transcripts are found in regions where inductive interactions occur between mesenchymal tissues and adjacent epithelium, for example, in the developing whisker follicles and the tooth bud (Jones et al. 1991). In addition, $B m p-4$ is expressed in a complex and dynamic pattern in the mesoderm and apical ectodermal ridge of the limb bud, at a time when pattern formation is taking place (Jones et al. 1991; Francis et al. 1994). Taken together, these studies suggest that BMP-4 is involved in mesoderm formation and patterning during and after gastrulation, and in mediating instructive in- 


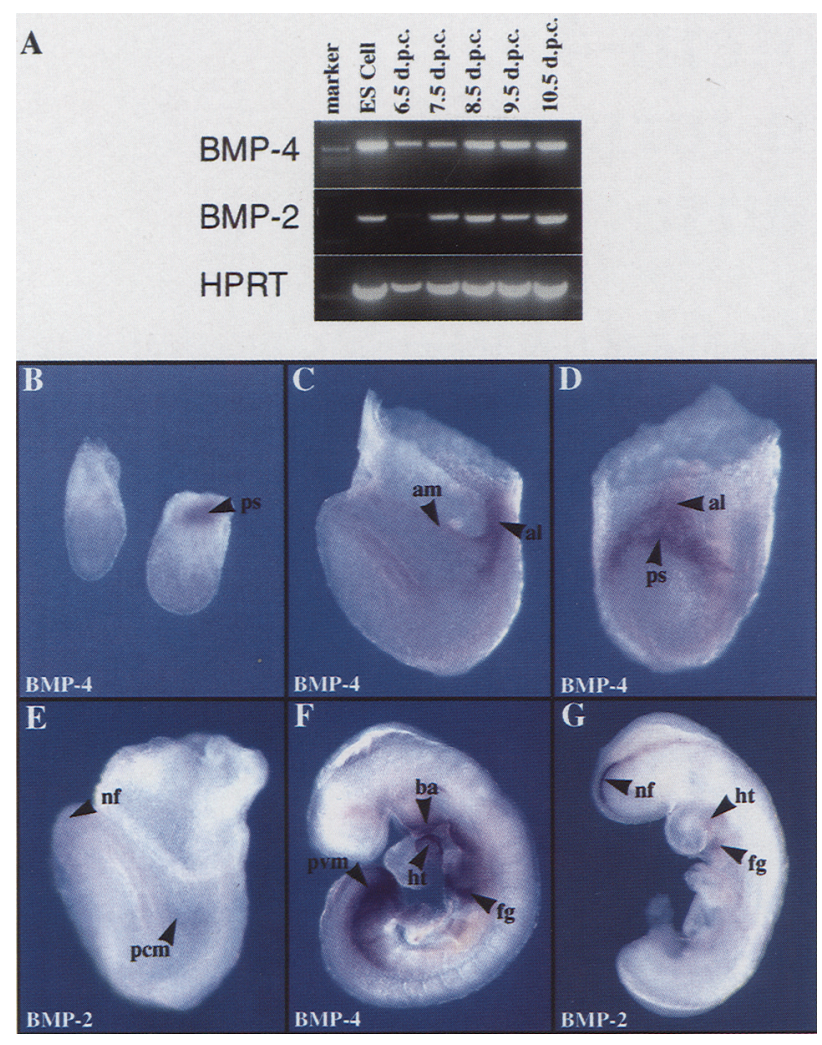

Figure 1. Expression of $B m p-2$ and $B m p-4$ in early mouse embryos. (A) RT-PCR was performed in triplicate using cDNA from undifferentiated ES cells and embryos between 6.5 and 10.5 days p.c. The resulting products were analysed by gel electrophoresis and ethidium bromide staining. Hypoxanthine phosphoribosyl transferase (HPRT) primers were used as an internal control for cDNA loading. (B) At 6.5 days p.c. Bmp-4 transcripts can be clearly localized by whole mount in situ hybridization in the posterior primitive streak (ps) of some embryos (arrow, right embryo) but is present at lower levels in the same location in others. $(C, D)$ Same 7.5-day p.c. early neural fold-stage embryo viewed from the side and posterior, respectively. Bmp-4 transcripts are seen in the amnion (am), allantois (al), and posterior primitive streak. (E) Bmp-2 RNA is localized in the anterior neural folds and presumed precardiac mesoderm $(\mathrm{pcm})$ (note lower background staining, cf. with $C) .(F)$ After turning, Bmp-4 RNA is seen at high levels in the branchial arches (ba), heart (ht), foregut $(\mathrm{fg})$, and posterior ventral mesoderm (pvm). (G) Bmp-2 RNA is highest in the anterior neural fold (nf) and in the heart (ht), foregut ( $\mathrm{fg}$ ) and allantois fout of focus).

teractions between many different cell types during development (for review, see Jones et al. 1991; Hogan et al. 1994). This hypothesis is reinforced by some in vitro studies with purifed protein. For example, BMP-4 enhances the differentiation of hematopoietic cells from murine embryonic stem (ES) cells in culture (Johansson and Wiles 1995) and in the tooth bud BMP-4 induces the expression of several genes in the dental mesenchyme, including the $B M P-4$ gene itself (autoinduction)/Vainio et al. 1993).

In addition to these studies with mouse embryos, there is strong experimental evidence that BMP-4 acts as $\exists$ ventralizing factor in mesodermal patterning during Xenopus development. Overexpression of BMP-4 leads to the up-regulation of posterior mesoderm markers such as Xhox-3, to the differentiation of ventral mesenchyme and blood cells in isolated animal caps, and to the duplization of the posterior body axis in "einsteck" experiments (Dale et al. 1992; Jones et al. 1992; Fainsod et al. 1994; Hogan et al. 1994). In addition, overexpression of a tominant negative BMP-2/4 type I receptor leads to a hyperdorsalized phenotype and the down-regulation of globin expression (Graff et al. 1994; Maeno et al. 1994; Suzuki et al. 1994). These results have led to a model in which BMP-4 expressed from maternal and zygotic transcripts before and during Xenopus gastrulation actively promotes the differentiation of ventral-posterior mesoderm and counteracts the opposing effect of dorsalizing factors such as activin (Jones et al. 1992; Fainsod et al. 1994; Graff et al. 1994; Harland 1994).

To define precisely the role of BMP-4 in mouse development a mutation was generated in the gene by homologous recombination in ES cells. Most homozygous $B m p-4^{t m 1 b l h}$ mutants are arrested at the egg cylinder stage and have little or no mesoderm. Some, however, develop to later stages but are grossly retarded and have defects in posterior structures. These results provide the first direct genetic evidence that BMP-4 is required at several different stages of mouse development, beginning with gastrulation and mesoderm formation.

\section{Results}

Expression of Bmp-2 and Bmp-4 in early mouse embryos

RNA for both Bmp- 2 and Bmp- 4 can be detected by RTPCR in embryos from 6.5 to 10.5 days p.c. (Fig. 1A). Using whole mount in situ hybridization, Bmp-2 transcripts cannot be localized in 6.5-day p.c. embryos, but low levels of Bmp-4 RNA can be seen in the posterior primitive streak (Fig. 1B). By 7.5 days p.c. some Bmp-2 RNA is detected in the anterior, just lateral to the neural folds and in presumed precardiac mesoderm (Fig. 1E), whereas Bmp-4 is expressed at highest levels in the posterior primitive streak, allantois, and amnion, with levels barely above background in the anterior neural region (Fig. 1C,D). Soon after turning, Bmp-2 is clearly expressed along the edges of the neural folds in the anterior, in the developing heart, and in the foregut (Fig. 1G). In contrast, Bmp-4 is localized to the posterior primitive streak, posterior-ventral mesoderm, the foregut, the branchial arches, and the heart (Fig. 1F).

\section{Targeted disruption of the mouse Bmp-4 gene}

As shown in Figure 2, A and B, and elsewhere (Feng et al. 1994) the mouse Bmp-4 gene consists of two proteincoding exons; the first encodes the signal sequence and about half of the amino-terminal pro region, whereas the second encodes the remainder of the pro region and all of the carboxy-terminal mature protein. In the targeted allele, here designated Bmp-4 $4^{\text {tm } 1 \text { blh }}$ (Davisson 1995), all of the coding sequence of the first exon after amino acid 
position 7 is replaced by the $\mathrm{MClneo}{ }^{\mathrm{r}} \mathrm{A}+$ cassette. In addition, an oligonucleotide encoding stop codon in all three reading frames is inserted into a unique SfiI site in the middle of the second exon. The rationale of this design was to terminate any protein initiated on an alternatively spliced or readthrough transcript incorporating the second coding exon. Therefore, it is expected that neither a full-length nor a potentially dominant negative truncated protein will be expressed from the Bmp$4^{\text {tm1blh }}$ allele.

\section{Phenotype of homozyous mutant embryos on a} (C57BL/6×129) hybrid genetic background

Initially, heterozygous Bmp-4tm1blh $/+(\mathrm{C} 57 \mathrm{BL} / 6 \times 129)$ $\mathrm{F}_{1}$ hybrids were intercrossed to generate homozygous and heterozygous embryos. These were collected between 7.5 and 10.5 days p.c. and identified by PCR analysis of yolk sac DNA. (This PCR analysis is dependent on the presence in the second protein coding exon of an oligonucleotide encoding stop codon in all three reading frames.) All embryos genotyped as homozygous Bmp$4^{\text {tm } 1 \text { blh }}$ were abnormal in phenotype, whereas all normal embryos were homozygous wild type or heterozygous mutant. The overall percentage of abnormal embryos (including empty decidua) generated by interbreeding either (C57BL/6 $\times 129$ ) hybrids or hybrids between the first and third generation of backcrossing to C57BL/6 was $26 \%$ (Table 1).

At each stage, the phenotype of $B m p-4^{t m 1 b l h}$ embryos was variable, even within a litter. In some cases all that was found was an empty deciduum, an empty yolk sac, or a very small and completely disorganized or dead embryo. In most cases mutants were arrested at the egg cylinder stage. More advanced mutant embryos ranged in phenotype from the neural fold/early somite stage (approximately Theiler stage 12) to a few embryos that had undergone turning and had a beating heart (Theiler stage 14-15) (Fig. 3). All mutants were smaller and grossly retarded compared with their littermates and had disorganized or truncated posterior structures. In addition, when compared with wild-type littermates the mutant visceral yolk sac often had a "blebby" appearance attributable to the paucity of extraembryonic mesoderm and blood islands underlying the endoderm layer (arrows, Fig. 3F,H).

\section{Phenotype of homozygous mutant embryos during backcrossing onto a C57BL/6 inbred genetic background}

To investigate the possible effect of genetic background on the homozygous mutant phenotype, hybrid (C57BL/ $6 \times 129$ ) heterozygous mutant females were backcrossed to $\mathrm{C} 57 \mathrm{BL} / 6$ inbred males. From the fourth to the ninth backcross generation (representing mice with between a $93.8 \%$ and $99.8 \%$ C57BL/6 genotype) embryos were collected between 3.5 and 10 days p.c. Taking empty decidua and abnormal embryos together, the overall percentage of putative homozygous mutants was $27 \%$ (Table 2). In addition, in all cases where genotyping could be done (by PCR analysis of yolk sac DNA), homozygous Bmp-4 ${ }^{\text {tm1blh }}$ embryos were abnormal compared with their heterozygous and $+/+$ littermates.

The phenotype of $B m p-4^{\text {tm } 1 \text { blh }}$ embryos still remained variable within a litter, and most failed to advance beyond the egg cylinder stage. Although the number of embryos is still small, at 9.5 days p.c. no homozygous mutant embryos beyond the neural fold/early somite stage have been recovered, raising the possibility that the mutant phenotype is somewhat more severe on the C57BL/ 6 background. Histological analysis of one of the most advanced abnormal embryos in this backcross group is shown in Figure 4A,C. One striking feature is the relative paucity of blood islands containing red blood cells in the mesoderm of the visceral yolk sac compared with a normal littermate (Fig. 4B,D). As noted above, this was a feature of all $B m p-4^{\text {tm } 1 \text { blh }}$ embryos that reached this stage of development and beyond. In addition, there were few red blood cells in the heart, dorsal aorta, and vessels of the embryo (Fig. 4A,B, arrowheads).

Most of the abnormal embryos were arrested at the egg cylinder stage. Sections of three such embryos analyzed at 7.5 days p.c. are shown in Fig. $4 \mathrm{E}-\mathrm{G}$, together with a normal littermate $(\mathrm{H})$. In all abnormal embryos a small amount of extraembryonic mesoderm can be distinguished (Fig. 4E-G, arrows) but an organized primitive streak is not present.

\section{Phenotype of homozygous mutant embryos on other genetic backgrounds}

Some of the founder chimeras were crossed with 129 females, and a colony of heterozygous $B m p-4^{\operatorname{tm} 1 b l h} /+$

Figure 2. Targeted inactivation of the $B m p-4$ gene in ES cells and mice. $(A)$ Genomic organization of the wild type and $B m p-4^{t m} 1 b l h$ alleles and structure of the replacement vector. Exons are represented by solid rectangles. In the replacement vector a $1.6-\mathrm{kb}$ genomic fragment containing the first protein-coding exon from amino acid position 7 and part of the following intron was replaced by the neomycin resistance cassette from $\mathrm{pMClneoA}+$. In addition, an oligonucleotide generating translational stop codons in all three reading frames was introduced into the single SfiI site in the second coding exon (open box), thereby destroying this site. The replacement vector has herpes virus thymidine kinase cassettes flanking the regions of homology. The open rectangles denote the 500-bp BamHI-BsmI fragment used as an external 5' probe and the 800-bp XbaI-BamHI fragment used as an internal 3' probe. (B) Details of the mutated second coding exon. The position of the SfiI site and the inserted oligonucleotide is shown with respect to the BMP-4 amino acid sequence. The positions of the primers used in the PCR-SfiI restriction analysis are denoted, together with the sizes of the PCR products derived from the wild-type and mutant second exon before and after SfiI digestion. (Inset) PCR-SfiI restriction analysis of yolk sac DNAs of three 9.5-day p.c. embryos derived from matings of heterozygous $B m p-4^{\text {tm } 1 b 1 h}$ mice. The 452 -bp band indicates the presence of the mutated second coding exon, the 210- and 230-bp fragments indicate the presence of the wild-type second coding exon. Accordingly, the genotypes of the embryos are definitively $+/+,+/-$, and $-/-$. (B) BamHI; $(B s) B s m I ;(C) C l a I ;(E)$ EcoRI; (Sf) SfiI; (Sp) SpeI; (X) XbaI; (Xh) XhoI. Restriction enzyme recognition sites in brackets were destroyed in the cloning process. 
inbred 129 mice was established. However, these have low fertility and most females with a copulation plug have failed to yield any embryos or decidual swellings.

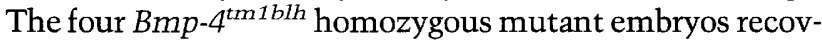

ered to date have been small and abnormal, resembling those shown in Figure 4, E-G, and Figure 5, B and C.

Some of the inbred $129 \mathrm{Bmp}-4^{\mathrm{tm} 1 \mathrm{blh}} /+$ males were crossed with outbred ICR females to generate $(\mathrm{ICR} \times 129)$

A

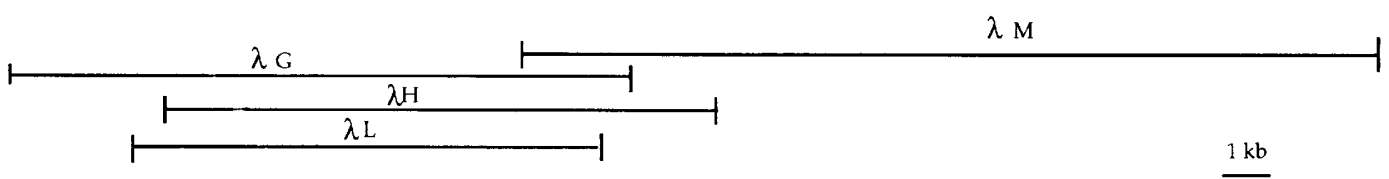

Wild-type allele
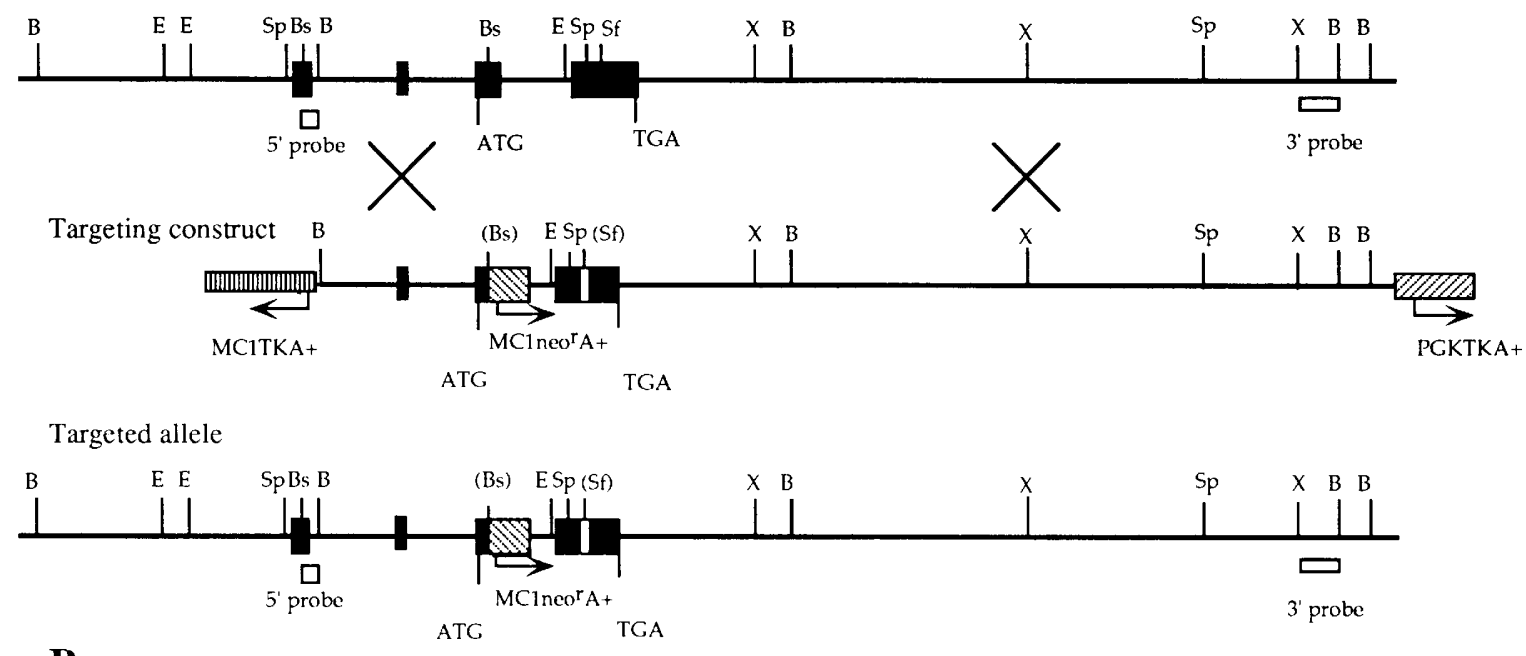

B

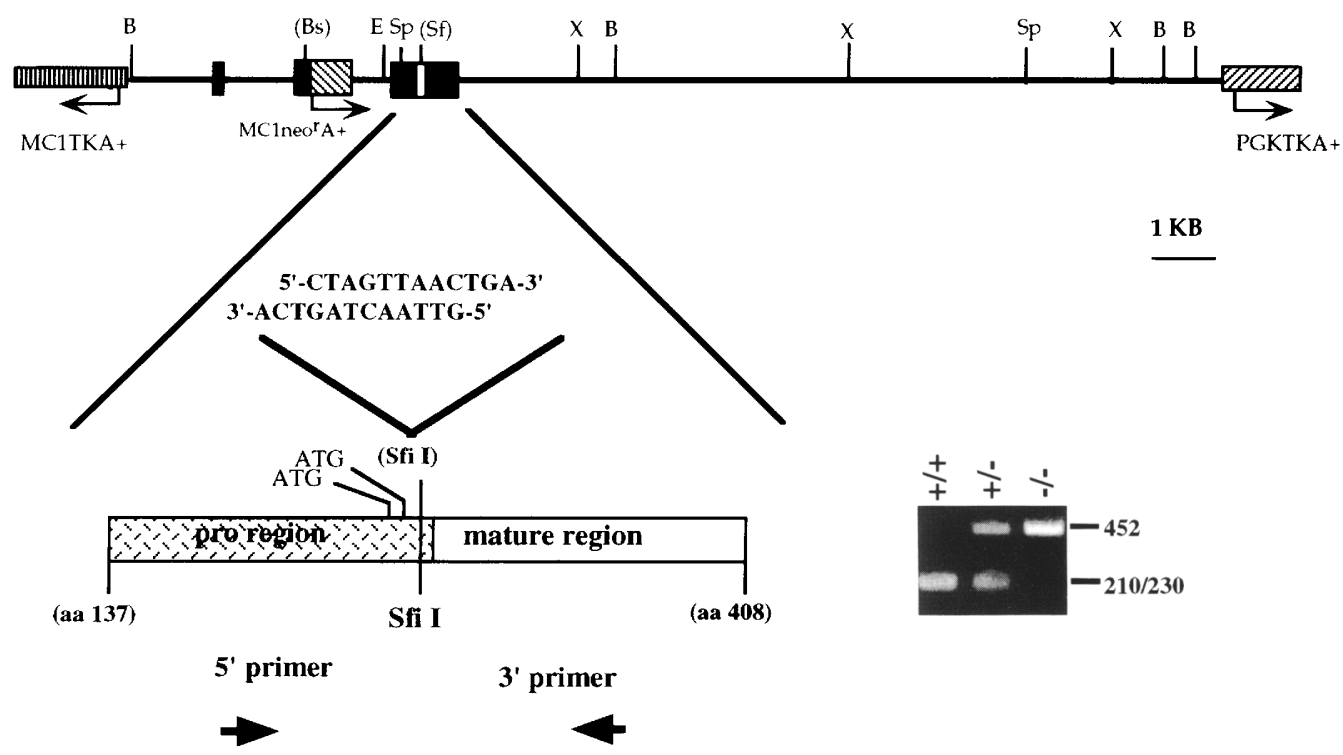

Sfi I

230 bp $\quad 210 \mathrm{bp}$

Wild-type PCR products sensitive to Sfi I

452 bp

BMP-4 tm1blh PCR product resistant to Sfi I

Figure 2. (See previous page for legend.) 
Table 1. Phenotypes observed during gestation

BMP- $4^{\text {tmlblh }} \times$ B6 backcross

$(129 \times \mathrm{B} 6)$ hybrids and generations $1-3$

\begin{tabular}{|c|c|c|c|c|c|c|c|c|}
\hline \multirow{2}{*}{$\begin{array}{c}\text { Age of } \\
\text { embryos (d.p.c.) }\end{array}$} & \multirow{2}{*}{$\begin{array}{l}\text { Total no. } \\
\text { of decidua }\end{array}$} & \multirow{2}{*}{$\begin{array}{c}\text { Normal } \\
1+1+\text { and }+1-1\end{array}$} & \multicolumn{5}{|c|}{ Abnormal $(-/-)$} & \multirow{2}{*}{$\begin{array}{l}\text { Empty decidua } \\
\text { (no.) }\end{array}$} \\
\hline & & & de & ec & hf & $\mathrm{t}$ & N.D. & \\
\hline 7.5 & 36 & 25 & 2 & 6 & 0 & 0 & 0 & 3 \\
\hline 8.5 & 83 & 54 & 0 & 0 & 0 & 0 & 17 & 12 \\
\hline 9.5 & 159 & 133 & 5 & 10 & 1 & 6 & 0 & 4 \\
\hline 10.5 & 39 & 25 & 3 & 2 & 0 & 1 & 0 & 8 \\
\hline Totals $\langle \%\rangle$ & 317 & $237(74 \%)$ & \multicolumn{5}{|c|}{$53(17 \%)$} & $27(9 \%)$ \\
\hline
\end{tabular}

(de) Dead embryo; (ec) egg cylinder; (hf) head-fold; (t) "turned;" (N.D.) not determined.

hybrids that were then interbred. The phenotype of embryos on this genetic background is summarized in Table 3. Taken together, empty decidua and abnormal embryos make up $24 \%$ of the total. Again, the phenotype of Bmp$4^{\text {tm1 } 1 \text { lh }}$ embryos is variable and at 9.5 and 11.5 days p.c. some have been recovered that are grossly retarded but have undergone turning, have a beating heart and forelimb buds, and resemble the embryo shown in Figure 3A.

\section{Abnormalities are not seen in homozygous mutants before $\sim 6.0$ days p.c.}

To determine the earliest stage at which the mutant phenotype could be detected, embryos were collected as blastocysts at 3.5 days p.c. and as egg cylinder stage embryos at 5.5 days p.c. soon after implantation, and genotyped by PCR. At both stages, all the homozygous Bmp-

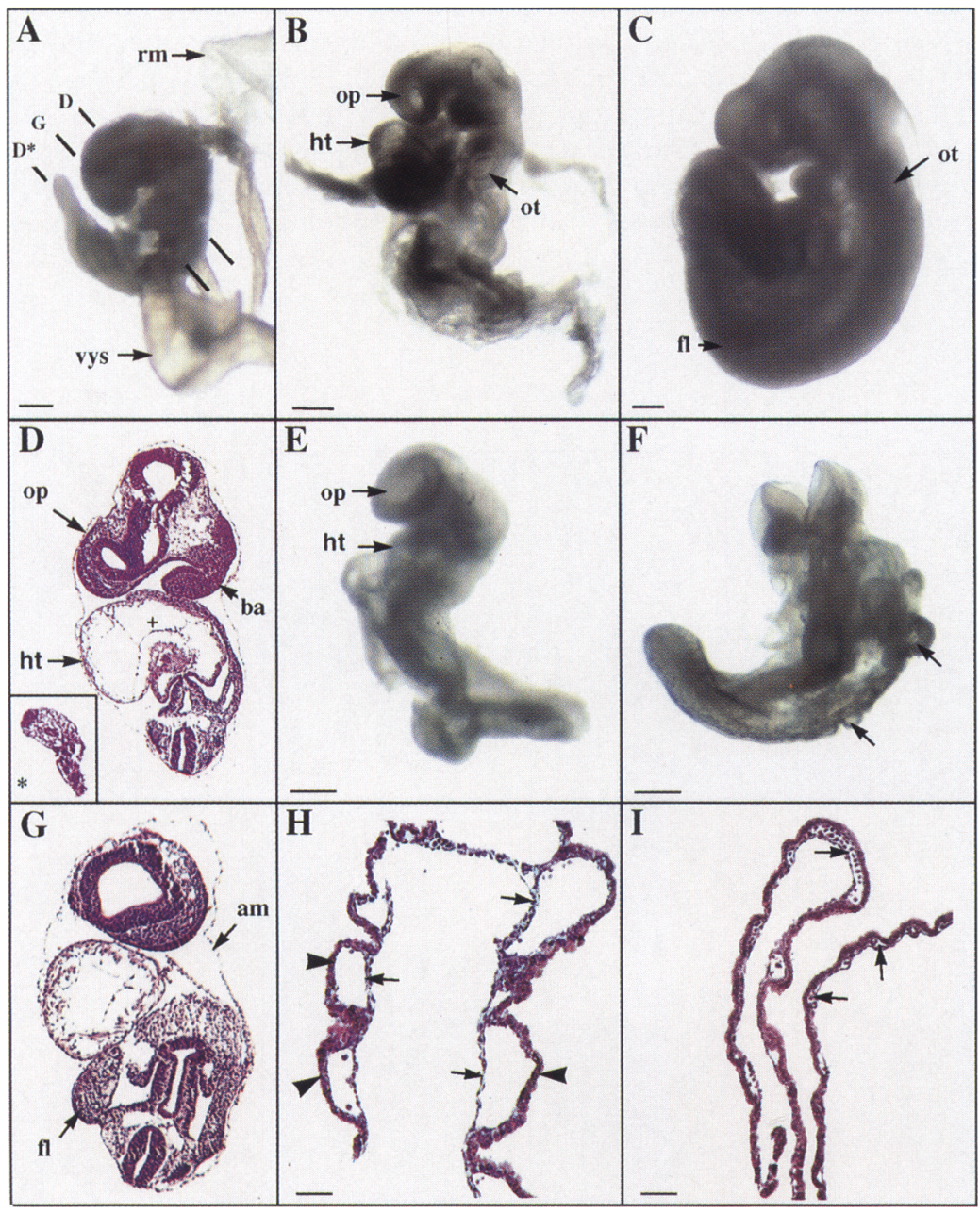

Figure 3. Phenotype of $B m p-4^{\text {tm } 1 b l h}$ and wildtype embryos at 9.5 days p.c. $(A, B, E, F)$ Homozygous mutant embryos as judged by PCR analysis of yolk sac DNA; $(C)$ a wild-type + / + littermate of $F$. They were obtained on the $(\mathrm{C} 57 \mathrm{BL} / 6 \times 129)$ hybrid background. All the homozygotes are smaller than normal (see scale bars) and retarded in development. $(D, G)$ Sections through the embryo shown in $A$ at the levels indicated. These and other sections show that embryo $A$ has optic (op) and otic vesicles, branchial arches (ba) 1, 2, and 3 , somites, forelimb bud (fl) and heart (ht). The posterior of the embryo is abnormal and shows only a small hind gut diverticulum and neural plate (inset * in $D$ ). Sections of the heart at the level of the atrioventricular cushion reveal an absence of mesenchymal cells in the region of the prospective cushions $(+\mid$ between the myocardium and the endocardium. Very few red blood cells are present in the heart and blood vessels. The embryo in $B$ has optic (op) and otic (ot) vesicles and a heart that was beating at the time of dissection. The posterior of the embryo is truncated. In $E$ the embryo has prominent optic vesicles and a heart, but the posterior is truncated and disorganized. In $F$ the neural folds are still open in the head region and the yolk sac has an abnormal blebby appearance (arrows). Viewed ventrally, the margin between the lateral body wall and the yolk sac has not begun to close around the ventral midgut region. $(H)$ Section through the visceral yolk sac from a 9.5-day homozygous mutant. Contact between the endoderm (arrowheads) and extraembryonic mesoderm (arrows) is very limited and few red blood cells are present. (I) Yolk sac from a 9.5-day wild-type embryo showing close apposition of endoderm and mesoderm and red blood cells in the numerous blood islands (arrows). $(A-F)$ Bars, $0.25 \mathrm{~mm}$; $(H, I)$ bar, $50 \mu \mathrm{m}$. 
Table 2. Phenotype observed during gestation

\begin{tabular}{|c|c|c|c|c|c|c|c|c|}
\hline \multicolumn{9}{|c|}{$\begin{array}{c}\text { BMP- } 4^{\text {tm } 1 \mathrm{blh}} \times \text { B6 backcross } \\
\text { generations } 4-9\end{array}$} \\
\hline \multirow{2}{*}{$\begin{array}{c}\text { Age of } \\
\text { embryos (d.p.c.) }\end{array}$} & \multirow{2}{*}{$\begin{array}{l}\text { Total no. } \\
\text { of decidua }\end{array}$} & \multirow{2}{*}{$\begin{array}{c}\text { Normal } \\
(+1+\text { or }+/-1\end{array}$} & \multicolumn{5}{|c|}{ Abnormal $(-/-)$} & \multirow{2}{*}{$\begin{array}{l}\text { Empty decidua } \\
\text { (no.) }\end{array}$} \\
\hline & & & de & ec & hf & $\mathrm{t}$ & N.D. & \\
\hline 6.5 & 15 & 11 & 0 & 4 & 0 & 0 & 0 & 0 \\
\hline 7.5 & 33 & 23 & 1 & 8 & 0 & 0 & 0 & 1 \\
\hline 8.5 & 24 & 18 & 1 & 3 & 1 & 0 & 0 & 1 \\
\hline 9.5 & 20 & 15 & 0 & 1 & 2 & 0 & 0 & 2 \\
\hline Totals $(\%)$ & 92 & $67(73 \%)$ & & & $21(23$ & & & $4(4 \%)$ \\
\hline
\end{tabular}

See Table 1 for abbreviations.

$4^{\text {tm } 1 \text { blh }}$ embryos appeared morphologically normal. This was the case with embryos either on a predominantly C57BL/ 6 background or on an $(\mathrm{ICR} \times 129)$ hybrid background (Table 4).

\section{Expression of molecular markers in homozygous mutant embryos}

To investigate mesoderm formation in mutants at the molecular level, Bmp-4 $4^{\text {tm1blh }}$ genotyped embryos arrested at the egg cylinder stage at 7.25 days (as judged by morphology under the dissecting microscope) were hybridized with a probe for $T$ (Brachyury). Normally this gene is expressed first in the mesoderm of the early primitive streak from $\sim 6.5$ days p.c. (Herrmann 1991). In the three homozygous mutant embryos examined in this way, no $T$ expression was detected. In contrast, both the normal 7.25-day p.c. littermates and wild-type embryos collected at 6.5 days p.c., at the onset of gastrulation, showed characteristic $T$ expression (Fig. 5A). This finding supports the morphological evidence (see Fig. 4) that those mutant embryos, which are arrested at the egg cylinder stage, generate little or no primitive streak mesoderm.

Abnormal embryos that had developed to the neural fold stage were analyzed for the expression of the caudallike homeodomain protein, Cdx-4/Gamer and Wright 1993|. Normally this is expressed first in the allantois and tip of the posterior primitive streak in 7.0- to 7.5-day p.c. embryos and later extends rostrally in the ectoderm and mesoderm of the posterior primitive streak. To maintain the relationship between the embryo and its extraembryonic membranes, immunohistochemistry was carried out on sections without dissecting the embryo from the deciduum, so that genotyping was not carried out and homozygous mutants were identified solely on the basis of abnormal morphology. No Cdx-4 expres-
Figure 4. Histological analysis of Bmp$4^{\text {tm1blh }}$ homozygous embryos at the sixth backcross generation to C57BL/6. Sections through an abnormal (presumed Bmp$4^{\text {tm1 blh }}$ ) embryo $(A)$ and its normal littermate $(B)$ at 8.5 days p.c. Both embryos had $\sim 8$ somites. Note in $A$ the visceral yolk sac with few blood islands and the small number of red blood cells in the ventral blood vessel (arrowhead) compared with $B .(C, D)$ Details of the visceral yolk sac from the boxed areas in $A$ and $B$. Note the paucity of extraembryonic mesoderm and red blood cells (arrows) in the presumed homozygous mutant $C$ compared with normal $D$. Visceral endoderm is labeled with arrowheads. $(E-G)$ Three presumed Bmp-4 $4^{\text {tm1blh }} \mathrm{mu}$ tants at 7.5 days. $(E)$ Littermate of the normal embryo shown in $H$. Normal littermates of $F$ and $G$ had the same morphology as $H$. Note the absence of an organized primitive streak in $F-G$, although a small amount of extraembryonic mesoderm appears to be present (arrows). (am) amnion; (al) allantois; (ps) primitive streak; (rm) Reichert's membrane. $(A, B)$ Bar, $200 \mu \mathrm{m}$; $(C, D)$ bar, $25 \mu \mathrm{m}_{\text {; }}(E-G)$ bar, $50 \mu \mathrm{m}(H)$ bar, $67 \mu \mathrm{m}$.

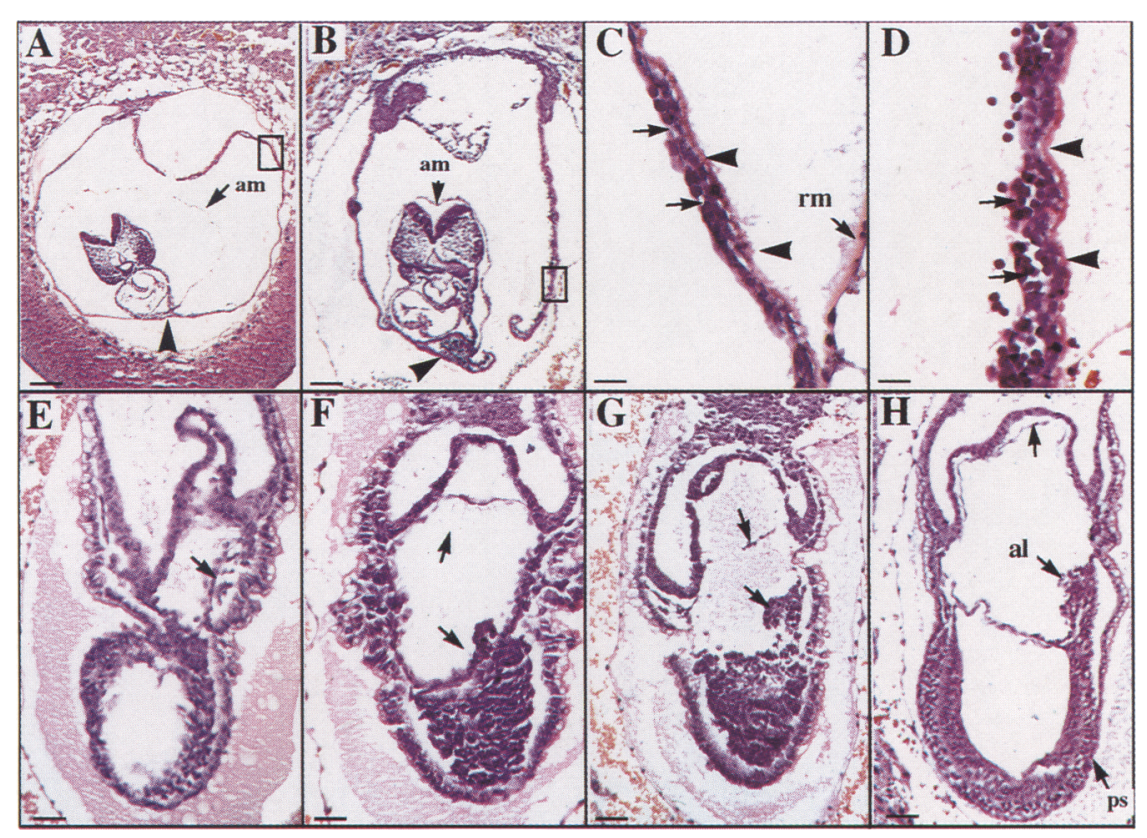




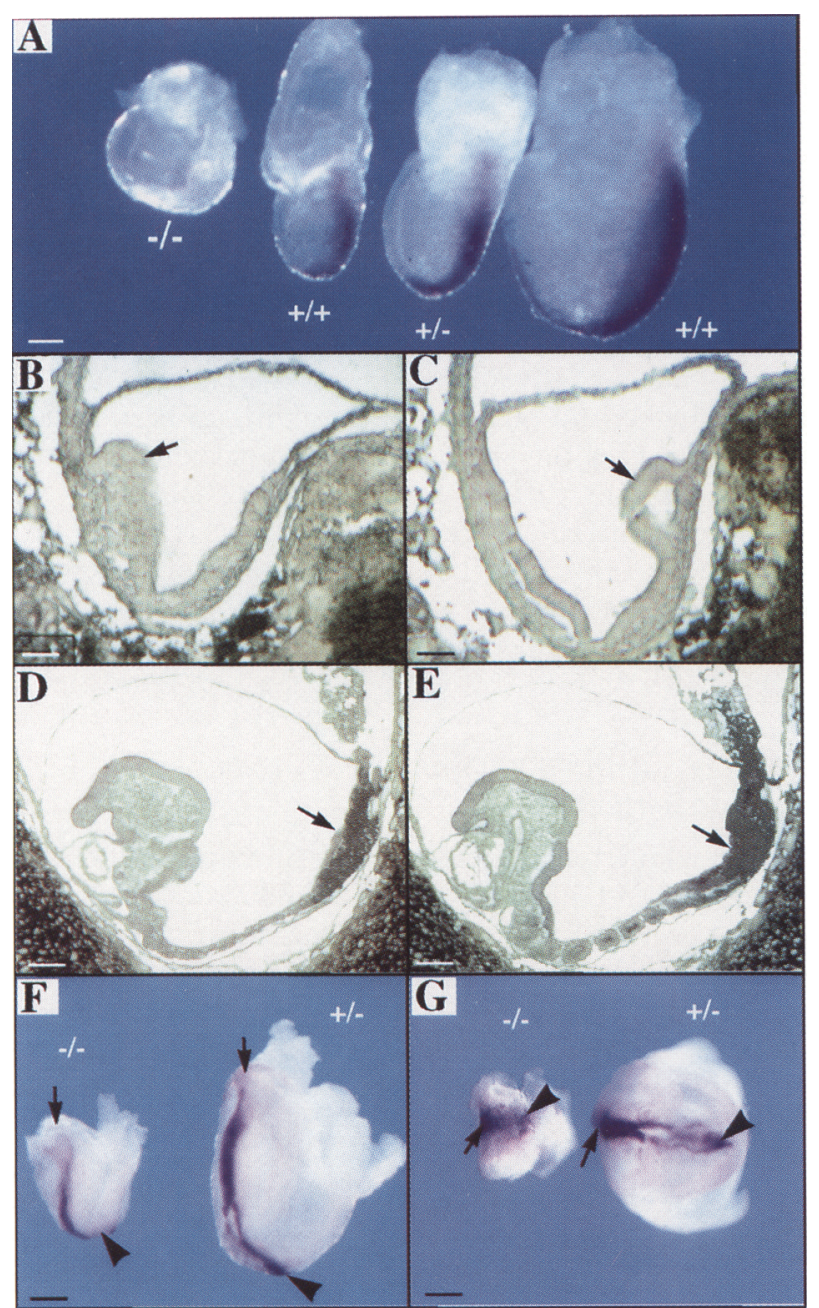

sion could be detected in the posterior of presumed Bmp$4^{\text {tm1blh }}$ embryos. This is illustrated in Figure 5, B-E, which compares a normal embryo at 8.5 days p.c. with a littermate with an abnormal posterior region that does not show $\mathrm{Cdx}-4$ expression.

Finally, embryos that had developed to the neural fold stage were examined for the expression of $H N F-3 \beta$. This gene encodes a winged-helix protein that is normally expressed in the anterior primitive streak, node, and noto-
Figure 5. Expression of mesodermal markers in mutant and wild-type embryos $(A) B m p-4^{\text {tm1blh }}$ mutants arrested early in development do not express $T$ (Brachyury). All embryos were genotyped by PCR analysis of extraembryonic DNA and were subjected to whole mount in situ hybridization at the same time. The embryo on the left is a $B m p-4^{\text {tm1 bih }}$ homozygous mutant at 7.25 days obtained by crossing mice at the sixth backcross generation on C57BL/6 (98.5\% C57BL/6). It does not express $T$ (Brachyury) as judged by whole mount in situ hybridization. The third embryo from the left is a heterozygous littermate. For comparison, the second embryo on the left and the embryo on the right are wild-type ICR embryos taken at 6.5 days and 7.5 days p.c., respectively. Absence of $T$ expression was observed in two other Bmp- $4^{\text {tm1blh }}$ mutants at $\sim 7.25$ days. $(B-E)$ Expression of $\mathrm{Cdx}-4$ protein by immunohistochemistry. $(B, C)$ Mid-sagittal and more lateral sections through an 8.5-day p.c. presumed $B m p-4^{\text {tm1blh }}$ embryo on the 129 background. In $B$ the arrow marks the anterior head fold. In $C$ the arrow marks an abnormal fold of the ectoderm in the posterior of the embryo. In neither section was staining with $\mathrm{Cdx}-4$ antibody observed. Orientation of the sections was confirmed by their relationship to a large blood sinus in the deciduum. $(D, E)$ Mid-sagittal and somewhat more lateral sections of a littermate showing strong Cdx-4 staining in the posterior of the embryo (arrows). $(F, G)$ Lateral and ventral views of homozygous and heterozygous mutant embryos at the seventh backcross generation on C57BL/ 6 after whole mount in situ hybridization with $H N F-3 \beta$. Embryos were genotyped by PCR analysis of extraembryonic DNA. The $B m p-4^{\text {tm } 1 b l h}$ mutant to the left shows a normal pattern of $H N F$ $3 \beta$ expression in the notochord underlying the anterior head fold (arrow) and in the node (arrowhead). The apparent bifurcation of the notochord in the $+1-$ littermate is a dissection artifact.

chord during gastrulation (Sasaki and Hogan 1993). Studies in other laboratories have shown that embryos homozygous for a null mutation in the fibroblast growth factor (FGF) receptor gene, $f g f r-1$, have a deficiency in posterior mesoderm and overexpress $H N F-3 \beta$ in the midline notochord region. This is thought to reflect the role of an FGF in promoting the proliferation and differentiation of posterior and paraxial mesoderm (Deng et al. 1995; Yamaguchi et al. 1995). In Bmp-4 $4^{\text {tm } 1 \text { blh }}$ embryos

Table 3. Phenotypes observed during gestation

\begin{tabular}{|c|c|c|c|c|c|c|c|c|}
\hline \multicolumn{9}{|c|}{$B m p-4^{t m 1 b l h} \times$ ICR hybrids } \\
\hline \multirow{2}{*}{$\begin{array}{c}\text { Age of } \\
\text { embryos (d.p.c.) }\end{array}$} & \multirow{2}{*}{$\begin{array}{l}\text { Total no. } \\
\text { of decidua }\end{array}$} & \multirow[b]{2}{*}{$+1+$} & \multirow[b]{2}{*}{$+1-$} & \multicolumn{4}{|c|}{$-1-$} & \multirow{2}{*}{$\begin{array}{c}\text { Empty decidua }{ }^{a} \\
|\%|\end{array}$} \\
\hline & & & & de & ec & hf & $\mathrm{t}$ & \\
\hline 6.5 & 44 & 10 & 19 & 1 & 3 & 0 & 0 & 10 \\
\hline 7.5 & 74 & 18 & 33 & 2 & 2 & 0 & 0 & 18 \\
\hline 8.5 & 58 & 18 & 34 & 1 & 2 & 0 & 0 & 6 \\
\hline 9.5 & 115 & 33 & 62 & 2 & 2 & 3 & 4 & 10 \\
\hline 10.5 & 39 & 10 & 14 & 1 & 0 & 2 & 10 & 0 \\
\hline 11.5 & 4 & 1 & 2 & 0 & 0 & 0 & 1 & 0 \\
\hline Total (\%) & 334 & $90(27 \%)$ & $164(49 \%)$ & & & & & $44(13 \%)$ \\
\hline
\end{tabular}

See Table 1 for abbreviations.

${ }^{a}$ For wild-type ICR mice the percentage of empty decidua was $3 \%(7 / 238)$. 
Winnier et al.

Table 4. Genotyping of pre-and peri-implantation embryos

\begin{tabular}{lcccccc}
\hline Background & $\begin{array}{c}\text { Age of embryos } \\
\text { (d.p.c) }\end{array}$ & Total & $+/+$ & $+1-$ & \multicolumn{2}{c}{$\begin{array}{c}\text { Empty decidua } \\
\text { (no.) }\end{array}$} \\
\hline C57BL/6 & 3.5 & 10 & 2 & 6 & 2 & N.A. \\
ICR & 3.5 & 22 & 6 & 13 & 4 & N.A. \\
ICR & 5.5 & 45 & 14 & 20 & 3 & 3 \\
Total $(\%)$ & & 77 & $22(29 \%)$ & $39(49 \%)$ & $14(18 \%)$ & $3(4 \%)$ \\
\hline
\end{tabular}

the pattern of expression of $H N F-3 \beta$ is essentially normal in the notochord and node (Fig. 5F,G).

\section{Discussion}

The results reported here provide the first direct genetic evidence that BMP-4 is essential for early mouse development. Although not all embryos were genotyped, the percentage of abnormal embryos and empty decidua together made up $\sim 25 \%$ of the total collected from heterozygous $B m p-4^{\text {tm } 1 b l h} /+$ crosses on all genetic backgrounds. Moreover, all homozygous Bmp-4 $4^{\text {tm1 } 1 \mathrm{blh}} \mathrm{em}-$ bryos genotyped were abnormal and all normal embryos genotyped were either wild type or heterozygous mutant (Tables 1-3; data not shown). Therefore, Bmp-4 is the second member of the TGF- $\beta$ gene superfamily shown by genetic evidence to be required for mesoderm formation and gastrulation in the mouse, the other being nodal (Zhou et al. 1993; Conlon et al. 1994). In contrast, homozygous null Bmp-5 and Gdf-5 mice are viable and fertile, although the adults do show defects in the skeletal system (Kingsley et al. 1992; Storm et al. 1994). Homozygous null activin $\beta A$ and activin $\beta B$ mice have relatively minor defects, for example, in ectodermal differentiation and craniofacial development, but show no abnormalities in gastrulation and mesoderm formation (Vassalli et al. 1994; Matzuk et al. 1995). Therefore, the most important questions that need to be addressed are (1) the nature of the specific processes in early development that require BMP-4, and (2) the reason for the variability in the phenotype of homozygous mutants.

The simplest hypothesis, summarized in Figure 6, and discussed in more detail below, is that BMP-4 is first required both for the proliferation and survival of epiblast cells just before gastrulation and for mesoderm formation. Beyond this stage, development of homozygous mutant embryos depends on the supply of exogenous BMP-4 from the maternal environment or on the ability of other signaling molecules to compensate for the absence of BMP-4. In the presence of these factors, development can proceed, albeit at a slower rate than normal, until the next step at which BMP-4 is required, for example, the differentiation and proliferation of posterior mesoderm fated to give rise to extraembryonic mesoderm of the amnion, allantois, and yolk sac and to ventral-lateral mesoderm in the embryo (Lawson and Pedersen 1992). Homozygous mutants may be arrested at this stage or proceed to the next stage at which a BMP4-dependent process is essential for embryo survival in the uterus (Copp 1995). For example, this might be the production of an adequate blood supply and circulatory system, fusion of the allantois with the chorion, or closure of the ventral body wall. According to this model, the variability of the phenotype of homozygous mutants is dependent in part on the stochastic nature of the processes involved and the availability of rescuing factors. In addition, it is possible that on some genetic backgrounds modifier genes influence the supply of rescuing factors or the dependence of complex processes on BMP-4.

\section{BMP-4 is essential for normal gastrulation and mesoderm formation}

We have found that homozygous mutant 3.5-day p.c. blastocysts and 5.5-day p.c. egg cylinder stage embryos appear normal, at least under the dissecting microscope. In contrast, abnormal embryos and empty decidua are first observed $\sim 6.5$ days p.c., the time when gastrulation begins (Tables 1-3) and when very low levels of $B m p-4$ transcripts have been detected in the embryo (Jones et al. 1991; Johansson and Wiles 1995; Fig. 1A). Abnormal Bmp- $4^{\text {tm } 1 b l h}$ embryos arrested at this stage do not express $T($ Brachyury), a marker for early primitive streak mesoderm (Herrmann 1991), although expression is seen in their heterozygous littermates (Fig. 5A). One possible explanation for these results is that BMP-4 is required for the survival and proliferation of epiblast cells at the time when they become competent to respond to mesoderminducing factors. An alternative hypothesis is that BMP-4 is required for the survival of newly differentiated mesoderm cells; in the absence of ligand the mesoderm dies and more epiblast cells differentiate to compensate, ultimately leading to the epiblast being depleted. A third hypothesis is that BMP-4 is acting solely as a mesoderminducing factor. However, if this were the case it might be expected that the epiblast would continue to proliferate without generating any mesoderm, giving rise to embryos with the phenotype seen in homozygous nodal or msd mutants (Conlon et al. 1994; Holdener et al. 1994). Further studies are required to distinguish between these possibilities. For example, it would be informative to culture blastocysts in vitro and test whether Bmp$4^{\text {tm1blh }}$ inner cell mass (ICM) cells continue to proliferate in vitro at the same rate as normal, and give rise to ES cell lines that generate mesoderm. A similar approach has been used to demonstrate a requirement for FGF- 4 in the proliferation of ICM and embryonic ectoderm cells (Feldman et al. 1995).

It is possible that the hypotheses outlined above are not mutually exclusive and that BMP-4 is required for both the proliferation of epiblast cells in the egg cylinder 


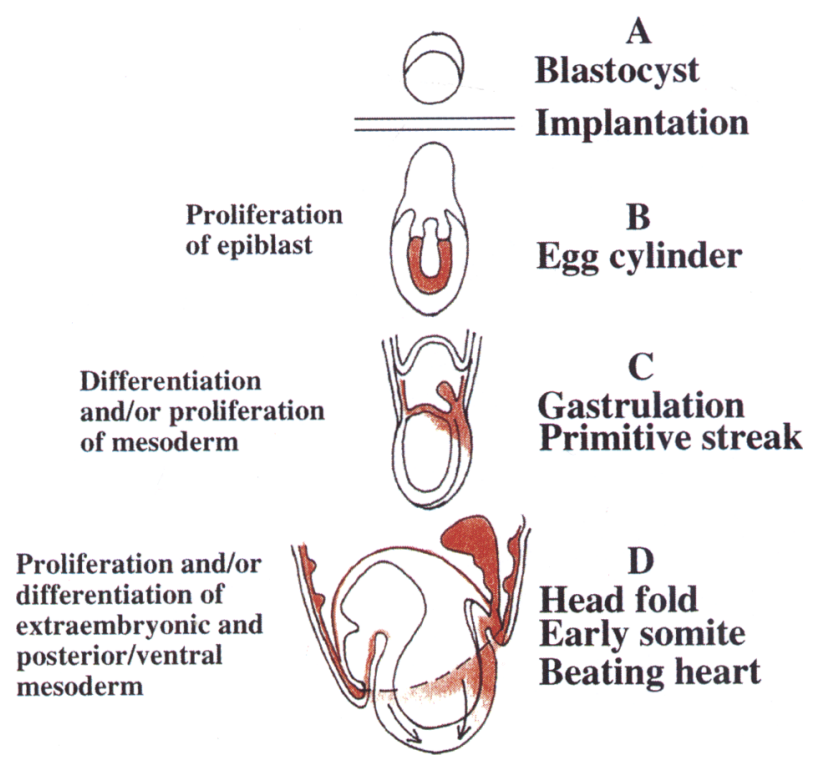

Figure 6. Model for the multiple requirements for BMP-4 in early mouse development. (A) Homozygous Bmp-4 $4^{\text {tm } 1 b l h}$ embryos appear normal at the blastocyst stage and at the early egg cylinder stage immediately after implantation (Table 4). (B) Bmp-4 transcripts can be detected at very low levels at 6.5 days p.c. (Jones et al. 1991; Johansson and Wiles 1995) and many homozygous Bmp-4 $4^{\text {tmiblh }}$ embryos do not develop beyond the egg cylinder stage and do not express $T($ Brachyury). Therefore, we propose that BMP-4 is required for the proliferation of epiblast cells (red) and for their differentiation into mesoderm. $(C)$ Some Bmp-4 ${ }^{\text {tm1blh }}$ homozygous mutants can be rescued by maternal BMP-4 or by BMP-2 expressed in the embryo and develop slowly to the primitive streak/head fold stage. However, there is a deficiency in posterior embryonic mesoderm and extraembryonic mesoderm in the allantois and visceral yolk sac, suggesting that BMP-4 is required for their proliferation or differentiation (red). Bmp-4 transcripts can be detected in these regions by whole mount in situ hybridization (data not shown). (D) Some Bmp-4tm1blh mutants can be rescued to the early somite/beating heart stage before or after turning. These embryos probably cease development because of a failure in the development of extraembryonic structures such as the blood islands and allantois, tissues in which Bmp-4 is expressed (red). There may also be a failure in the growth of the lateral plate mesoderm so that the margins between the yolk sac and the amnion, and the spanchopleure and somatopleure do not move ventrally (arrows) to close along the ventral midline of embryo during and after turning.

and for their differentiation into mesoderm. In Xenopus and Drosophila embryos, BMP-4 and DPP appear to function by specifying the fate of cells in the marginal zone and blastoderm, respectively. In the mouse this function of regulating cell fate may be conserved but linked to the control of cell proliferation. A somewhat similar conclusion has been reached by two groups studying the role of FGF in early mouse development. In the absence of a signal from the FGF receptor-1 (FGFR-1), cells in the primitive streak appear to proliferate more slowly than normal and to differentiate preferentially into axial rather than paraxial mesoderm (Deng et al. 1995; Yamaguchi et al. 1995). However, a marked expansion of
$H N F-3 \beta$-expressing axial mesoderm compared with normal was not seen in $B m p-4^{\text {tm } 1 b l h}$ homozygous embryos (Fig. 5F,G).

Our hypothesis that BMP-4 is essential for gastrulation is strongly supported by the phenotype of embryos homozygous for a likely null mutation in the Bmpr gene, which encodes a BMP-2/4 type I serine-threonine kinase trans-membrane receptor (Mishina et al. 1995). Homozygous mutant embryos die at $\sim 6.5$ days, are small in size, and do not form mesoderm, as judged by the absence of expression of a number of early mesoderm markers, including T(Brachyury) (Y. Mishina and R.R. Behringer, pers. comm.).

\section{Development of BMP-4 $4^{\text {tm } 1 \mathrm{blh}}$ embryos beyond gastrulation}

Although BMP-4 appears to be first required for gastrulation some homozygous $B m p-4^{\text {tm1 } 1 b l h}$ mutants develop beyond this stage (Tables 1-3). One possibility is that these embryos are rescued by maternal BMP- 4 diffusing in from decidual cells, which express Bmp-4 RNA at 6.5 and 7.5 days (Jones et al. 1991). Alternatively, embryonic BMP-2, which is $92 \%$ identical to BMP-4 in the mature region, may compensate for the absence of BMP-4, particularly if its expression is up-regulated in the homozygous mutant. Bmp-2 is expressed in the embryos from 6.5 days p.c. and in some tissues (amnion, allantois, heart) its localization overlaps with that of $B \mathrm{mp}-4$ (Fig. 1A,B; Lyons et al. 1995). Transcripts for two other members of the BMP superfamily, Vgr-2 (Gdf-3) and BMP-7, have been detected in the 6.5- and 7.5-day p.c. embryo (Jones et al. 1992; Lyons et al. 1995) but they encode proteins with only $50 \%-60 \%$ sequence identity to BMP4 , and might not be expected to signal through the same or closely related receptors. The hypothesis that some homozygous Bmp-4tm1blh embryos are being rescued by BMP-2 is supported by the fact that no homozygous Bmpr mutants, which lack a type 1 receptor are capable of binding both BMP-2 and BMP-4, develop beyond the egg cylinder stage (Y. Mishina and R.R. Behringer, pers. comm.).

Assuming that some rescue of $B m p-4^{\text {tm } 1 \text { blh }}$ mutants is possible, then gastrulation could occur and development proceed, albeit more slowly than normal, to the next stage when a BMP-4-dependent process becomes ratelimiting. This appears to be the proliferation and differentiation of the mesoderm of the posterior primitive streak, which is fated to give rise to the extraembryonic mesoderm of the yolk sac and allantois and to the ventral-lateral mesoderm of the posterior body wall and gut. This conclusion is based on several observations. First, in all $B m p-4^{\text {tm1 } 1 b l h}$ embryos that develop beyond the neural fold/early somite stage there is a deficiency of mesoderm cells and blood islands in the visceral yolk sac, often leading to a blebby appearance of the yolk sac (Fig. $3 \mathrm{~F}, \mathrm{H})$. Also, in sections of embryos that develop a heart and vascular system, the number of red blood cells seen inside these structures is greatly reduced compared with normal (Figs. 3D,G and 4A). In addition, the allantois is often relatively small (see Fig. $3 \mathrm{~F}$ ) and the posterior of the 
embryo truncated and disorganized (Figs. 3A,B and 5B,C). This is manifested at the molecular level by the absence of Cdx-4 staining the posterior of abnormal embryos (Fig. $5 \mathrm{~B}-\mathrm{E})$. Finally, in some embryos that reach the stage of "turning," the ventral aspect of the body wall appears more "open" than normal (for example, see Fig. 3E,F). The process of turning involves a major realignment of the embryo and its extraembryonic membranes. In particular, the margins between the lateral body wall and the yolk sac, and the body wall and the amnion, have to shift ventrally and close down to a narrow ventral umbilical ring (Kaufman 1992) (see Fig. 6D). Although very little is known about the mechanisms underlying this process of ventral body wall closure, it probably requires extensive proliferation of the ventral-lateral mesoderm of the somatopleure and splanchopleure, tissues in which Bmp-4 transcripts are expressed at high levels (Jones et al. 1991).

According to our model, in the early mouse embryo BMP-4 is required for the differentiation of mesoderm derived from the posterior primitive streak and for the development of the ventral-lateral mesoderm of the body wall and gut (somatopleure and splanchnopleure). This conclusion is compatible with studies on both the expression of BMP-4 in Xenopus embryos (Fainsod et al. 1994) and its function as a ventralizing factor (for review, see Harland 1994). For example, we and others have shown that in Xenopus BMP-4 promotes the differentiation of posterior-ventral mesoderm, including hematopoietic tissue, and these cell types are deficient in $B m p-4^{t m 1 b l h}$ embryos that develop beyond gastrulation. In addition, our findings support the speculation that the dorsal-ventral axis of invertebrate and vertebrate embryos has been inverted during evolution (Arendt and Nubler-Jung 1994). This is based in part on the finding that DPP is a dorsalizing factor in Drosophila, whereas the closely related ligand BMP-4 behaves as a ventralizing factor in both Xenopus and early mouse embryos.

Expression studies in the later mouse embryo have suggested that BMP-4 is required for the development of a number of different structures, including the heart, limb, skin, diencephalon, and teeth (Jones et al. 1991). Although limb buds and heart did develop in some Bmp$4^{\text {tm1blh }}$ embryos, they appeared less well developed than those of normal littermates (Fig. 3D,G). However, it is not possible to determine whether this is attributable to a specific requirement for BMP-4 in these organs or to a secondary delay in overall development attributable to defects in other systems (e.g., the hematopoietic system). In the future, techniques such as tissue-specific gene targeting could be used to investigate more directly the role of BMP-4 in organ development in older embryos.

\section{The effect of genetic background on the phenotype of BMP- $4^{\text {tm } 1 \text { blh }}$ embryos}

If our model outlined above and in Figure 6 is correct, there are several ways in which the genetic background of the embryo or the mother could affect the phenotype of homozygous Bmp-4 tm1bih embryos. For example, there could be genetic differences in the synthesis and accumulation of rescuing factors such as maternal BMP-4 or embryonic BMP-2 or in the relative affinity of trans-membrane signaling receptors for BMP-4 and BMP2 . In addition, there could be genetic differences in the extent to which specific developmental processes such as posterior mesoderm proliferation and differentiation are dependent on one class of signaling molecule rather than another, for example, on FGFs compared with BMPs. One way to address these possibilities is to generate mice carrying various combinations of mutations in genes encoding different ligands and receptors, and such experiments are under way.

\section{Materials and methods \\ Construction of the targeting vector}

Genomic clones were isolated from a $129 / \mathrm{Sv}$ mouse $\lambda$ genomic library (Stratagene) using a $m B m p-4$ cDNA probe. Four overlapping $\lambda$-clones $(\lambda G, \lambda H, \lambda L, \lambda M)$ were isolated and partial sequencing and Southern blot analysis revealed the structure of the mBMP-4 gene as shown in Figure 2A. A replacement vector was constructed in a pBR322 derivative (Blessing et al. 1993) using as the $5^{\prime}$ homology region a $3.1-\mathrm{kb}$ fragment spanning from the BsmI site in the first coding exon (amino acid position 7 in the leader sequence) to an upstream BamHI site. The entire insert of clone $\lambda M$, spanning from a Sau3A site in the intron between the two coding exons to a Sau $3 \mathrm{~A}$ site $18.4 \mathrm{~kb}$ downstream, was used as the $3^{\prime}$ homology region. This was modified by inserting a short DNA fragment consisting of the two partially complementary oligonucleotides $5^{\prime}$-CTAGTTAACTGA$3^{\prime}$ and $5^{\prime}$-GTTAACTAGTCA-3' into the single SfiI restriction site located in the second coding exon just upstream of the DNA sequence coding for the mature region of BMP-4. This insertion destroys the SfiI restriction site and introduces stop codons in all reading frames (Fig. $2 \mathrm{~B}$ ). To facilitate positive/negative selection, thymidine kinase cassettes derived from the constructs pMClTKA + and pPGKTKA + (Rudnicki et al. 1992) were attached to the ends of the homology regions (Fig. 2). The neomycin/G418 resistance cassette derived from the construct pMClneo ${ }^{\mathrm{r}} \mathrm{A}+$ replaced $1.6 \mathrm{~kb}$ of genomic DNA consisting of the first coding exon from codon position 7 in the leader peptide and a part of the following intron. According to standard nomenclature (Davisson 1995) the mutant allele is designated here as $B m p-4^{t m 1 b l h}$.

\section{Electroporation and selection of ES cells}

ES cells $\left(5 \times 10^{7}\right)$ of line D3 (kindly provided by Dr. Tom Doetchman, University of Cincinnati, $\mathrm{OH}$ ) at passage 15 were electroporated with $200 \mu \mathrm{g}$ of NotI-digested replacement vector DNA in a total volume of $800 \mu \mathrm{l}$ of PBS using a single pulse from a gene pulser (Bio-Rad) at $800 \mathrm{~V}$ and $3 \mu \mathrm{F}$. The cells were then plated onto irradiated neor primary mouse embryo fibroblasts in Dulbecco's modified Eagle medium (DMEM) without sodium pyruvate (Specialty Media) containing 15\% fetal bovine serum (Hyclone) and supplemented with nonessential amino acids $(0.01 \mathrm{~mm})$, L-glutamine $(0.1 \mathrm{~mm}), 50 \mu \mathrm{g} / \mathrm{ml}$ of gentamycin sulfate, $0.0006 \% \beta$-mercaptoethanol (Sigma), and $1000 \mathrm{U} / \mathrm{ml}$ of ESGRO. Unless otherwise stated, all supplements were from GIBCO-BRL. Selection was initiated after $24 \mathrm{hr}$ by adding geneticin (GIBCO-BRL) at a final concentration of $300 \mu \mathrm{g} / \mathrm{ml}$ and, $48 \mathrm{hr}$ later, gancyclovir (Syntex) at a final concentration of $2 \times 10^{-6} \mathrm{M}$. Cells were kept under selection for $7-10$ days with a daily change of medium. Colonies were picked and replated 
without selection into duplicate 96 -well cell culture dishes, one of which contained a feeder layer of irradiated embryonic fibroblasts. After 2 days, the cells growing on feeders were frozen in $10 \%$ DMSO, $30 \%$ serum and stored at $-70^{\circ} \mathrm{C}$ and the duplicate plate was used to prepare genomic DNA for Southern blotting and PCR analysis. Of 288 double-resistant colonies screened, 48 were found to have a correctly targeted allele, giving an overall frequency of 1 in 6 . Southern blot analysis with a Neo probe showed only a single insert (data not shown).

\section{Southern blotting and PCR-SfiI restriction analysis}

For DNA extraction, ES cells, tail biopsies, yolk sac fragments, and embryos were lysed in $[100 \mathrm{~mm}$ Tris- $\mathrm{HCl}(\mathrm{pH} 7.5), 50 \mathrm{~mm}$ EDTA, $0.5 \%$ SDS, $0.1 \mathrm{mg} / \mathrm{ml}$ of proteinase $\mathrm{K}$ ] and digested overnight at $56^{\circ} \mathrm{C}$. DNA was prepared by phenol chloroform extraction and ethanol precipitation and redissolved in TE $(10 \mathrm{~mm}$ Tris- $\mathrm{HCl}$ at $\mathrm{pH} 7.5,0.1 \mathrm{~mm}$ EDTA). Southern blots were performed essentially as described (Church and Gilbert 1984). The $5^{\prime}$ probe (Fig. 2) is a 500-bp BamHI-BsmI fragment. The expected sizes for DNA digested with SpeI are $6.5 \mathrm{~kb}$ for the wildtype allele and $6.0 \mathrm{~kb}$ for the BMP-4 ${ }^{\mathrm{tm} 1 \mathrm{blh}}$ allele. The internal $3^{\prime}$ probe is a 800 -bp $\mathrm{XbaI}-\mathrm{BamHI}$ fragment located at the end of the 3' homology arm. This hybridized with a $12-\mathrm{kb}$ fragment in both wild-type and targeted alleles after digestion of genomic DNA with BamHI.

PCR-SfiI restriction analysis was performed using one primer identical to a sequence $\left(5^{\prime}\right.$-CCAGACTAGTCCATCACAATG$\left.3^{\prime}\right) 230 \mathrm{bp}$ upstream of the SfiI restriction site in the second coding exon and the other identical to a sequence $\left(5^{\prime}\right.$-TTGAGGTGATCAGCCAGTGGA-3') on the reverse strand $210 \mathrm{bp}$ downstream of the same SfiI restriction site (Fig. 2B). After amplification using Vent DNA polymerase (New England Biolabs), according to the manufacturer's instructions, the PCR products were subjected to $S$ fiI restriction enzyme digestion and analyzed on a $1.5 \%$ agarose gel. The product derived from the wild-type second exon will be cleaved by SfiI and yield 210- and 230-bp fragments, whereas the product from the mutated second exon will remain as a 452-bp fragment (Fig. 2B).

\section{Generation of chimeras and colonies of mice heterozygous for the Bmp-4 targeted allele}

ES cells from four targeted clones were injected in C57BL/ 6 host blastocysts that were implanted into pseudopregnant females as described (Hogan et al. 1995). The resulting chimeras were bred to C57BL/ 6 females and agouti offspring analyzed for the presence of the $B m p-4^{t m 1 b l h}$ allele by Southern blotting. Thirteen chimeras from one cell line, B286, transmitted the mutation through the germ line. Heterozygous offspring were either interbred or backcrossed with C57BL/6 inbred males. This colony is currently at the ninth backcross generation. The chimeras were also bred to 129 / Sv females, generating a colony of heterozygous Bmp-4tm1blh $/+129 / \mathrm{Sv}$ inbred mice. These were also crossed to outbred ICR mice (Harlan Sprague-Dawley) to generate $(129 \times$ ICR $) F_{1}$ hybrids.

For collecting embryos, heterozygous males and females were mated and noon on the day of plug taken as 0.5 days p.c. The embryos were genotyped using PCR-SfiI restriction analysis on DNA obtained from a part of the yolk sac.

\section{$R T-P C R$}

RT-PCR was performed as described (Johansson and Wiles 1995). Briefly, total RNA was isolated from ES cells and embryos between 6.5 and 10.5 days p.c. by an adaptation of the $\mathrm{LiCl} /$ urea method of Auffrey et al. (1980). The ES cells (line
TL1) were cultured for two passages in the absence of mouse embryo fibroblasts, and embryos of one age were pooled. Three independent cDNA syntheses were carried out, using three different RNA samples from each stage examined. cDNA was synthesized using oligo(dT) and the PCR was quantified using hypoxanthine phosphoribosyltransferase (HPRT) as an internal standard. The Bmp-2 and Bmp-4 primers were designed as described by Johansson and Wiles (1995). the HPRT primer sequences are $5^{\prime}$ primer $\left(5^{\prime}\right.$ to $\left.3^{\prime}\right)$ TTGTTGGATTTGAAATTCCAGACAAG and $3^{\prime}$ primer GCATTTAAAAGGAACTGTTGACAACG. The expected length of the cDNA amplification product is $648 \mathrm{bp}$, whereas the genomic DNA length is $1.3 \mathrm{~kb}$.

\section{Whole-mount in situ hybridization}

This was performed essentially as described (Sasaki and Hogan 1993) with minor modifications. For example, $2 \%$ Boehringer Mannheim blocking reagent was used in addition to $10 \%$ heatinactivated serum to block nonspecific sites and Boehringer Mannhein purple-precipitating reagent was used instead of NBT-BCIP as the coloring reagent.

\section{Immunohistochemistry}

This was performed as described (Gamer and Wright 1993) using a 1:100 dilution of $\mathrm{Cdx}-4$ antibody.

\section{Acknowledgments}

We thank Linda Hargett for excellent technical assistance, Laura Gamer for antibody to murine CDX-4, Richard Woychick for introducing us to the Panorama program for keeping mouse breeding records, and Christopher Wright, Richard Behringer, Lucy Liaw, and Elizabeth Robertson for critical and helpful comments on the manuscript. This work was supported by HD28955. P.A.L. is an Associate and B.L.M.H., an Investigator of the Howard Hughes Medical Institute.

The publication costs of this article were defrayed in part by payment of page charges. This article must therefore be hereby marked "advertisement" in accordance with 18 USC section 1734 solely to indicate this fact.

\section{References}

Arendt, D and K. Nubler-Jung. 1994. Inversion of dorsoventral axis? Nature 371: 26.

Auffrey, C., R. Nageotte, B. Chambraud, and F. Rougeon. 1980. Mouse immunoglobulin genes: A bacterial plasmid containing the entire coding sequence for a pre-gamma $2 \mathrm{a}$ heavy chain. Nucleic Acids Res. 8: 1231-1241.

Blessing, M., L.B. Nanney, L.E. King, C.M. Jones, and B.L.M. Hogan. 1993. Transgenic mice as a model to study the role of TGF- $\beta$-related molecules in hair follicles. Genes \& Dev. 7: 204-215.

Campbell, G., T. Weaver, and A. Tomlinson. 1993. Axis specification in the developing Drosophila appendage: The role of wingless, decapentaplegic, and the homeobox gene aristaless. Cell 74: 1113-1123.

Church, G.M. and W. Gilbert. 1984. Genomic sequencing. Proc. Natl. Acad. Sci. 81: 1991-1995.

Conlon, F.L., K.M. Lyons, N. Takaesu, K.S. Barth, A. Kispert, B. Herrmann, and E.J. Robertson. 1994. A primary requirement for nodal in the formation and maintenance of the primitive streak in the mouse. Development 120: 1919-1928.

Copp, A.J. 1995. Death before birth: Clues from gene knockouts and mutations. Trends Genet. 11: 87-93.

Dale, L., G. Howes, B.M.J. Price, and J.C. Smith. 1992. Bone morphogenetic protein 4: A ventralizing factor in early Xe- 
nopus development. Development 115: 573-585.

Davisson, M.T. 1995. Trends in Genetic Nomenclature Guide, p. 36.

Deng, C.-X., A. Wynshaw-Boris, M.M. Shen, C. Daugherty, D.M. Ornitz, and P. Leder. 1995. Murine FGFR-1 is required for early postimplantation growth and axial organization. Genes \& Dev. 8: 3045-3057.

Diaz-Benjumea, F.J. and S.M. Cohen. 1993. Interaction between dorsal and ventral cells in the imaginal disc directs wing development in Drosophila. Cell 75: 741-752.

Fainsod, A., H. Steinbeisser, and E.M. De Robertis. 1994. On the function of $B M P-4$ in patterning the marginal zone of the Xenopus embryo. EMBO I. 13: 5015-5025.

Feldman, B., W. Poueymirou, V.E. Papaioannou, T.M. DeChiara, and M. Goldfarb. 1995. Requirement of FGF-4 for postimplantation mouse development. Science 267: 246-249.

Feng, J.Q., M.A. Harris, N. Ghosh-Choudhury, M. Feng, G.R. Mundy, and S.E. Harris. 1994. Structure and function of mouse bone morphogenetic protein-2 gene (BMP-2): Comparison of the structures of BMP-2 and BMP-4 genes. Biochim. Biophys. Acta 1218: 221-224.

Francis, P.H., M.K. Richardson, P.M. Brickell, and C. Tickle. 1994. Bone morphogenetic proteins and a signalling pathway that controls patterning in the developing limb bud. Development 120: 209-218.

Gamer, L.W. and C.V.E. Wright. 1993. Murine Cdx-4 bears striking similarities to the Drosophila caudal gene in its homeodomain sequence and early expression pattern. Mech. Dev. 43: 71-81.

Graff, J.M., R.S. Thies, J.J. Song, A.J. Celeste, and D.A. Melton. 1994. Studies with a Xenopus BMP receptor suggest that ventral mesoderm-inducing signals override dorsal signals in vivo. Cell 79: 169-179.

Harland, R.M. 1994. The transforming growth factor $\beta$ family and induction of the vertebrate mesoderm: Bone morphogenetic proteins are ventral inducers. Proc. Natl. Acad. Sci. 91: 10243-10246.

Herrmann, B.G. 1991. Expression pattern of the brachyury gene in whole-mount $\mathrm{T}^{\mathrm{wis}} / \mathrm{T}^{\mathrm{wis}}$ mutant embryos. Development 113: 913-917.

Hogan, B.L.M. 1995. The TGF- $\beta$-related signalling system in mouse development. Semin. Dev. Biol. (in press).

Hogan, B.L.M., M. Blessing, G.E. Winnier, N. Suzuki, and C.M. Jones. 1994. Growth factors in development: The role of TGF- $\beta$ related polypeptide signalling molecules in embryogenesis. Development (Suppl.) 53-60.

Holdener, B.C., C. Faust, N.S. Rosenthal, and T. Magnuson. 1994. $\mathrm{msd}$ is required for mesoderm induction in mice. $D e$ velopment 120: 1335-1346.

Johansson, B.M. and M.V. Wiles. 1995. Evidence for involvement of activin $A$ and bone morphogenetic protein 4 in mammalian mesoderm and haematopoietic development. Mol. Cell. Biol. 15: 141-151.

Jones, C.M., K.M. Lyons, and B.L.M. Hogan. 1991. Involvement of bone morphogenetic protein-4 (BMP-4) and Vgr-1 in morphogenesis and neurogenesis in the mouse. Development 111: $531-542$.

Jones, C.M., K.M. Lyons, P.M. Lapan, C.V.E. Wright, and B.L.M. Hogan. 1992. DVR-4 (bone morphogenetic protein-4) as a posterior-ventralizing factor in Xenopus mesoderm induction. Development 115: 639-647.

Kaufman, M.H. 1992. The atlas of mouse development. Academic Press, San Diego, CA.

Kingsley, D.M. 1994. What do BMPs do in mammals? Clues from the mouse short-ear mutation. Trends Genet. 10: 16-22.

Kingsley, D.M., A.E. Bland, J.M. Grubber, P.C. Marker, L.B. Rus- sell, N.G. Copeland, and N.A. Jenkins. 1992. The mouse short ear skeletal morphogenesis locus is associated with defects in a bone morphogenetic member of the TGF $\beta$ superfamily. Cell 71: 399-410.

Lawson, K.A. and R.A. Pedersen. 1992. Clonal analysis of cell fate during gastrulation and early neurulation in the mouse. Postimplanation development in the mouse. CIBA Found. Symp. 165: 3-26.

Lyons, K.M., B.L.M. Hogan, and E.J. Robertson. 1995. Colocalization of BMP 7 and BMP 2 RNAs suggests that these factors cooperatively mediate tissue interactions during murine development. Mech. Dev. 50: 71-83.

Maeno, M., R.C. Ong, Y. Xue, S.-I. Nishimatsu, N. Ueno, and H.-F. Kung. 1994. Regulation of primary erythropoiesis in the ventral mesoderm of Xenopus gastrula embryo: Evidence for the expression of a stimulatory factor(s) in animal pole tissue. Dev. Biol. 161: 522-529.

Matzuk, M.M., T.R. Kumar, A. Vassalli, J.R. Bickenbach, D.R. Roop, R. Jaenisch, and A. Bradley. 1995. Functional analysis of activins during mammalian development. Nature 374: 354-356.

Mishina, Y., A. Suzuki, D.J. Gilbert, N.G. Copeland, N.A. Jenkins, N. Ueno, and R.R. Behringer. 1995. Genomic organization and chromosomal location of the mouse type $1 \mathrm{BMP}-$ 2/4 receptor. Biochem. Biophys. Res. Comm. 206: 310-317.

Padgett, R.W., J. Wozney, and W.M. Gelbart. 1993. Human BMP sequences can confer normal dorsal-ventral patterning in the Drosophila embryo. Proc. Natl. Acad. Sci. 90: 2905-2909.

Rudnicki, M.A., T. Braun, S. Hinuma, and R. Jaenisch. 1992. Inactivation of MyoD in mice leads to up-regulation of the myogenic HLH gene Myf- 5 and results in apparently normal muscle development. Cell 71: 383-390.

Sampath, T.K., K.E. Rashka, J.S. Doctor, R.F. Tucker, and F.M. Hoffmann. 1993. Drosophila transforming growth factor beta superfamily proteins induce endochondral bone formation in mammals. Proc. Natl. Acad. Sci. 90: 6004-6008.

Sasaki, H. and B.L.M. Hogan. 1993. Differential expression of multiple fork head related genes during gastrulation and axial pattern formation in the mouse embryo. Development 118: 47-59.

Storm, E.E., T.V. Huynh, N.G. Copeland, N.A. Jenkins, D.M. Kingsley, and S.-J. Lee. 1994. Limb alterations in brachypodism mice due to mutations in a new member of the TGF $\beta$ superfamily. Nature 368: 639-643.

Suzuki, A., R.S. Thies, N. Yamaji, J.J. Song, J.M. Wozney, K. Murakami, and N. Ueno. 1994. A truncated bone morphogenetic protein receptor affects dorsal-ventral patterning in the early Xenopus embryo. Proc. Natl. Acad. Sci. 91: 1025510259.

Vainio, S., I. Karavanova, A. Jowett, and I. Thesleff. 1993. Identification of BMP-4 as a signal mediating secondary induction between epithelial and mesenchymal tissues during early tooth development. Cell 75: 45-58.

Vassalli, A., M.M. Matzuk, A.R. Gardner, K.-F. Lee, and R. Jaenisch. 1994. Activin/inhibin $\beta \beta$ subunit gene disruption leads to defects in eyelid development and female reproduction. Genes \& Dev. 8: 414-427.

Wall, N.A. and B.L.M. Hogan. 1994. TGF- $\beta$ related genes in development. Curr. Opin. Genet. Dev. 4: 517-522.

Yamaguchi, T.P., K. Harpal, M. Henkemeyer, and J. Rossant. 1995. fgfr-1 is required for embryonic growth and mesodermal patterning during mouse gastrulation. Genes \& Dev. 8: 3032-3044.

Zhou, X., H. Sasaki, L. Lowe, B.L.M. Hogan, and M.R. Kuehn. 1993. Nodal is a novel TGF- $\beta$-like gene expressed in the mouse node during gastrulation. Nature 361: 543-547. 


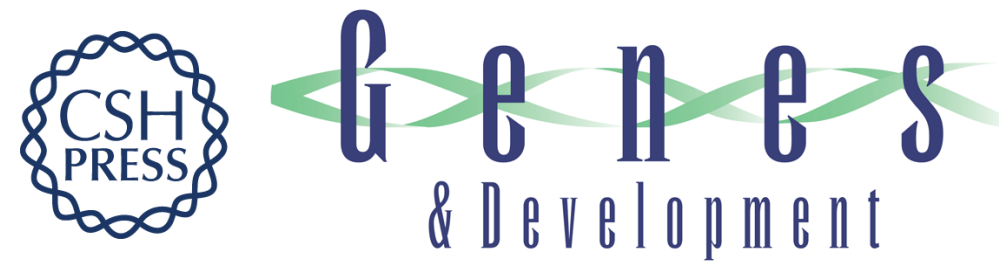

\section{Bone morphogenetic protein-4 is required for mesoderm formation and patterning in the mouse.}

G Winnier, M Blessing, P A Labosky, et al.

Genes Dev. 1995, 9:

Access the most recent version at doi:10.1101/gad.9.17.2105

References This article cites 40 articles, 17 of which can be accessed free at:

http://genesdev.cshlp.org/content/9/17/2105.full.html\#ref-list-1

License

Email Alerting

Service

Receive free email alerts when new articles cite this article - sign up in the box at the top right corner of the article or click here.

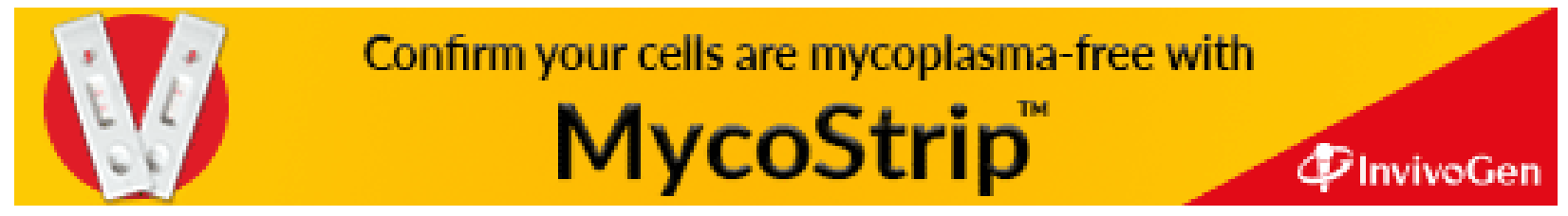

